\title{
Libro: La política universitaria de los gobiernos Kirchner: continuidades, rupturas, complejidades \\ Adriana Chiroleu, Mónica Marquina y Eduardo Rinesi (compiladores) \\ Universidad Nacional de General Sarmiento, Los Polvorines, 2012 (338 pp.)
}

\section{Daniela Atairo}

Profesora e investigadora de la Universidad Nacional de La Plata, Argentina.

E-mail: danatairo@yahoo.com.ar

Este libro se propone analizar las medidas adoptadas entre 2003 y 2010 y define el período como Tiempos interesantes, a partir de la vocación transformadora que habilita a pensar otros principios organizativos del orden social, en el cual la política adquiere mayor centralidad y autonomía, expandiendo el horizonte de lo que hasta entonces se aceptaba como posible. En ese sentido, el análisis de las continuidades y cambios o rupturas con la etapa anterior se convierte en un eje central que atraviesa a los diferentes artículos, además de explorar en qué medida esta vocación transformadora, que se expresa en ámbitos diversos de la vida nacional, se plasma en el sector universitario.

Esta publicación es una nueva producción de la Riepesal (Red Interuniversitaria para el Estudio de las Políticas de Educación Superior de América Latina), que se inicia con un encuentro en diciembre de 2009 en el cual se presentaron las primeras versiones de los textos que se fueron enriqueciendo tanto por la discusión interna del grupo como por las sugerencias de evaluadores externos. Como se señala en la introducción al libro, la pluralidad de pensamiento, que se plasma tanto en las diferentes perspectivas teóricas como en los posicionamientos frente a las políticas nacionales, es una de sus características relevantes.

Esta compilación realizada por Adriana Chiroleu, Mónica Marquina y Eduardo Rinesi, se conforma de cuatro partes que organizan un total de trece artículos. Por tal motivo, reseñarlo en un breve escrito se convierte en un desafío. En este sentido, hemos decidido seleccionar algunos ejes de análisis que nos permiten articular las hipótesis de los trabajos, buscando los matices que cada uno aporta. Creemos que allí está la riqueza del libro. Pero como cada artículo tiene una lógica en sí misma, esta decisión, por supuesto, deja por fuera muchos aportes que cada lector podrá retomar a partir de sus intereses específicos. Esta decisión deja también por fuera la posibilidad de hacer referencia a los marcos conceptuales a partir de los cuales los autores plantean sus hipótesis y la complejidad que muchos de sus argumentos plantean.

Como decíamos el libro se destaca por las diferentes posiciones teóricas y políticas pero también se pueden identificar puntos de encuentro entre varios de los autores. Uno de ellos es el reconocimiento de un giro en el papel del Estado al recuperar cierta centralidad y protagonismo en algunas de sus funciones. Suasnábar y Rovelli lo definen como un giro hacia un neointervencionismo estatal. Otro 
acuerdo es el reconocimiento de "avances en el sector" con respecto al período anterior, como el aumento de presupuesto sostenido dirigido hacia las universidades así como también el aumento en el área de Ciencia y Técnica y su jerarquización con la creación del Ministerio. Para algunos autores estos avances se inscriben en el marco de un proyecto democrático popular en el que las políticas inclusivas tienen su correlato en el ámbito universitario, y para otros autores se ha gobernado poco en materia universitaria respecto de otras áreas y los cambios positivos se producen en paralelo a la permanencia de una gran cantidad de dispositivos originados en los años '90 que instalaron prácticas difíciles de remover sin una política integral.

Entre aquellos autores que sostienen que la agenda y las medidas adoptadas no otorgan una nueva dirección al sistema universitario, se evidencian puntos de encuentro respecto de las razones (Chiroleu e Iazzetta, Suasnábar y Rovelli, Marquina). La búsqueda de cierta gobernabilidad del sector y de reducción del conflicto con un sector que históricamente le fue esquivo y resistente, parece ser un argumento central. Marquina señala que algunas decisiones privilegian dar respuesta a la presión política de las autoridades universitarias manteniendo al sector relativamente calmo, lo que genera un espacio libre para la política que retoma criterios que históricamente caracterizaron al sector.

En diferentes artículos se hace referencia al papel que los rectores de las universidades nacionales tienen en la construcción de la política universitaria: en la introducción de fórmulas para la distribución de nuevas partidas como señala Marquina; en la formulación de programas para el desarrollo de la ciencia y la tecnología en áreas nacionales consideradas prioritarias y de vacancia como señalan Korsunsky y Campero; desplazando a los expertos en la construcción de la política como señalan Suasnábar y Rovelli. Ello se corresponde con la descripción que presenta Marengo sobre las noticias donde los rectores aparecen como actores activos que reclaman, denuncian, proponen, solicitan, trabajan.

\section{- $\quad$ Límites a la construcción de una política}

Varios autores reconociendo los avances en el sector ponen el énfasis en señalar que la voluntad de revisar algunas políticas provenientes de los años ' 90 no incluyó centralmente al ámbito universitario. En este sentido, Chiroleu e Iazzetta sostienen que se postergó la formulación de una política universitaria integral, o articulada en términos de Burke. Lo que se evidencia en una multiplicidad de iniciativas aisladas y fragmentadas que no bastan para construir una política universitaria integral que marque un nuevo rumbo. Compartiendo estos postulados Marquina concluye que este conjunto de medidas tampoco suponen una intromisión gubernamental en la autonomía universitaria como sí sucedía durante la década del noventa en la cual los programas especiales eran estímulos para llevar adelante reformas en el sector.

La lectura del libro en su totalidad permite sostener que si se observan los programas especiales, los mismos no parecen dar cuenta de una política porque se presentan como fragmentados, diversos, discontinuos y al representar un porcen- 
taje reducido del presupuesto no alcanzan a tener un impacto en la introducción de nuevas prácticas, distintas a las ya instaladas durante el período anterior. Ahora bien, sí se reconoce una política de infraestructura, de aumento de presupuesto y de expansión institucional que modifica las condiciones de trabajo de los docentes como las de aprendizaje de los alumnos.

\section{- Un pendiente: la ley}

Chiroleu e Iazzetta consideran que una nueva ley no cambiará mágicamente la realidad ni las prácticas de las universidades argentinas, aunque aportaría sin duda un encuadre más adecuado poniéndolas en sintonía con el nuevo clima de ideas que se distancia de las aplicadas en los años '90. Además, los autores señalan que el sentido común indicaba que este proceso se daría naturalmente luego de la sanción de las otras tres leyes que regulan los otros niveles. En este sentido, la sanción de una nueva ley que reemplace la 24.521 se convierte en términos simbólicos como un pendiente. En los artículos se señalan que durante los años 2006, 2007 y 2008 se mantiene en el discurso la promesa de una nueva legislación para el sector. Aunque según el análisis de Marengo sobre la prensa escrita, la sanción o reforma de la ley no logró inscribirse de manera eficaz y sostenida como problemática de peso como sí lo fue el tema del financiamiento universitario.

- $\quad$ Límites a la construcción de una nueva agenda universitaria

Un tema en la agenda de gobierno revela tanto las prioridades como la voluntad política de ofrecer respuestas a un problema. En el libro se plantea que la cuestión universitaria quedó rezagada en una agenda de gobierno caracterizada como audaz por Chiroleu e Iazzetta y ambiciosa y heterodoxa por Suasnábar y Rovelli, que evidencia una posición reparadora frente a las políticas neoliberales de la década pasada.

Según Suasnábar, hacia el 2005 la agenda de políticas se inscribía entre la inercia anterior y la búsqueda de un rumbo diferente para el sector. Avanzados los años, la conformación de la misma no parece modificar la dirección de la educación superior tanto para Chiroleu e Iazzetta como para Suasnábar y Rovelli. La agenda se conforma de los siguientes temas: calidad, pertinencia, inclusión e internacionalización. Algunos de ellos están problematizados en la prensa escrita, especialmente el tema de la inclusión a través de problemáticas como ingreso-egreso y la articulación entre escuela secundaria y universidad, como señala Marengo.

En este sentido, la agenda se forma con nuevos temas como la inclusión, pertinencia e internacionalización. El primero parece haberse convertido en el articulador de varias políticas desde la expansión institucional hasta el sostenimiento de programas de becas y bienestar estudiantil, como lo plantea Rinesi. El segundo retoma concepciones históricas que articulan a la universidad más con la sociedad que con el mercado. El tercero, por su parte, se articula con tendencias más generales asociadas a los procesos de globalización. Por otro lado, la calidad es el punto de continuidad entre dos agendas de políticas construidas en el marco de paradigmas sociales y educativos diferentes. A pesar de la continuidad, su sentido 
y significado parecen ser objeto de disputa. Para algunos autores como Chiroleu e Iazzetta, las políticas de evaluación plantean desde el discurso de la Secretaría de Políticas Universitarias (SPU) una intención de tomar distancia de la concepción de calidad de los años '90, ligada a la eficiencia aunque dentro del mismo encuadre legal, documentos y pautas técnicas. Por su parte Burke sostiene una continuidad debido a la escasa presencia de propuestas alternativas y el reconocimiento por parte del Estado que la evaluación y la acreditación constituyen prácticas habituales en las instituciones universitarias. De todos modos, la autora reconoce un cambio en el rol del Estado en tanto se destinan fondos para financiar políticas de mejoras surgidas de los procesos de acreditación a través del Programa de Calidad de la Educación Superior (ES). Sobre el mismo programa, Casajús y Garatte rescatan las percepciones de algunos funcionarios de la SPU que se distancian del discurso oficial al considerar que los programas de mejoramiento son producto de las presiones de las asociaciones de decanos para que el Estado financie sus planes de mejoras resultados de las acreditaciones. Para estos mismos funcionarios existe una política desde el Ministerio de Educación de "dejar hacer" a los rectores, a los decanos, o "de no hacer política". Estas ideas ponen en tensión aquellas otras que refieren a un cambio en el rol del Estado en materia de educación superior que se articula con las otras medidas adoptadas a nivel nacional. Por otro lado, la percepción de "vía libre" a las universidades es corroborada con las percepciones de los actores en la base del sistema.

- Aumento sostenido del presupuesto y cambios incrementales en el modo de distribución

El monto presupuestario que se asigna directamente a las universidades se señala, en varios artículos, como uno de los avances más importantes con respecto al período anterior. Por ejemplo, Marquina analiza la tendencia de aumento del presupuesto teniendo en cuenta diferentes índices de inflación y considera que el incremento quebró la continuidad de 10 años de congelamiento y retraso del sector. Ahora bien, el cambio en las reglas de juego durante los años ' 90 supuso nuevas condiciones para la transferencia del subsidio público a las universidades y los programas especiales fueron la principal herramienta para impulsar reformas. Esta modalidad de gobierno y regulación de la ES en líneas generales continúa, según Suasnábar y Rovelli y se profundiza lentamente modificando la práctica histórica de distribución al introducir nuevas y diversas modalidades. Según los datos que muestra Marquina, de 2004 a 2010 la transferencia directa bajó del 96 al $91 \%$, por lo que una parte bien importante sigue siendo transferida directamente, aunque se van introduciendo cambios como los adicionales que se distribuyen por fórmulas producto de discusiones y acuerdos que ha impulsado el Consejo Interuniversitario Nacional (CIN) y aumentando la cantidad de Programas Especiales que comenzaron a implementarse en los años ' 90 desde la SPU.

A pesar de que la proporción de fondos destinados a programas implementados desde la SPU apenas supera el 5\% según los datos que presenta Marquina, se evidencia un crecimiento cuantitativo de programas. Suasnábar y Rovelli señalan que 
en 2003 se implementaban 5, lo que se triplica para el año 2006 alcanzando los 14 , y se duplica ese número en 2009 al llegar a los 30 programas. Los autores presentan un análisis de los programas y muestran una diversidad de orientaciones: programas "focalizados" hacia el mejoramiento de las disciplinas, carreras e instituciones son los que marcan una innovación en la intervención estatal; programas "competitivos" que dan continuidad a programas implementados a mediados de la década de los '90; programas más "accesibles" para el conjunto de las universidades; programas más "direccionados" que involucra a las grandes y medianas y programas "concertados" entre las universidades y la SPU. Desde el punto de vista de la continuidad de los programas, Marquina señala que se han sostenido aquellos destinados a promover la igualdad de oportunidades como el Programa Nacional de Becas así como también dentro de los programas de desarrollo, el programa destinado a incremento de dedicaciones docentes. Y desde 2007 asumen con fuerza y continuidad los programas de mejoramiento de carreras de interés público. Asimismo una cantidad considerable de programas demuestran la existencia de políticas esporádicas.

- Expansión institucional: planificación, inclusión, lógicas políticas

Cuando se abandona a nivel discursivo la promesa de una nueva ley, se inicia, según Chiroleu e Iazzetta, una política de expansión institucional frente a la cual el CIN manifestó diferencias respecto a lo promovido por el gobierno nacional. Pérez Rassetti considera que esta política tiene mucho de continuidad con el período anterior. La Ley de Educación Superior de 1995 regula y limita la creación de universidades públicas pero especialmente privadas a partir de los procesos de evaluación de los proyectos de creación de nuevas universidades que lleva adelante la Comisión Nacional de Evaluación y Acreditación Universitaria (CONEAU). Reconoce sin embargo, que las grandes líneas actuales de política universitaria otorgan un sentido totalmente diferente a la política de creación de nuevas universidades en los últimos años. Además señala la existencia de una política nacional explícita que supone la aceptación de ciertas lógicas locales que son asumidas con compromiso y acompañamiento político, además del lanzamiento del Programa de Diagnóstico y Evaluación para la expansión de la ES.

Respecto de la racionalidad subyacente a la expansión institucional, que claramente no depende de una planificación estratégica, Pérez Rasetti sostiene que es el resultado de una configuración de prácticas políticas sectoriales en distintos ámbitos y su conjunción con determinadas coyunturas; mientras que Chiroleu e Iazzetta consideran que están ligadas directamente a demandas de los líderes de partidos mayoritarios. La posición de Rinesi corre el foco, y no centra la mirada en las lógicas y razones que motorizaron la expansión, sino en el efecto altamente democratizador que tuvo la expansión asociada a la ampliación de derechos educativos y sociales en línea con la obligatoriedad de la escuela secundaria que establece la Ley de Educación Nacional de 2006. Esta situación, según Krichesky, plantea el desafío de articular las políticas universitarias, las de formación docente y las dirigidas al nivel medio para hacer verdadera y legítima la inclusión social y educativa. 
Por otro lado, el crecimiento del sistema se produce hacia arriba con la proliferación de los posgrados, en términos de modalidades con la Educación a Distancia $(\mathrm{EaD})$ y con la inscripción de instituciones dependiente de otros ministerios en el Sistema de Educación Superior (SES). En este sentido, Mazzola sostiene que la expansión del posgrado se dio sobre la construcción de un conjunto de mitos que generan una desarticulación entre los tipos de posgrados, con la investigación y con el grado. La ausencia de articulación está asociada según el autor a una ausencia de política consistente de posgrado. En lo que respecta a la EaD, Aranciaga plantea que existe un desafío de construir una política que reoriente las tendencias mercantilizadoras que tuvo esta modalidad durante la década pasada. Y que dicho desafío debería partir de reconocer el potencial democratizador que tiene la $\mathrm{EaD}$ si se concibe el diseño de procesos virtuales a partir de incorporar la tecnología a las prácticas educativas. Finalmente, Soprano y Frederic, describen el proceso por el cual los institutos militares se inscriben dentro del SES profundizado las estrategias de ciudadanización y de civilización de la formación militar en Argentina, en el marco de tendencias internacionales. Dicho proceso se vio favorecido por la Ley de 1995 y supuso la participación de estos institutos en los procesos de evaluación y acreditación de la CONEAU. 